\title{
Effect of micropyle orientation on germination of Millettia ferruginea and Delonix regia
}

\author{
Tadele Zewdie and Kebede Welka*
}

\begin{abstract}
Introduction: In order to solve the problems related to deforestation and meet the ever increasing demands of the growing population, conserving and wise utilization of the remaining forests and supporting it with additional tree planting are crucial. Proper understanding of efficient management technique including seed sowing methods for target species is vital. Research reports and other information on proper positioning of micropyles in field conditions are lacking for Millettia ferruginea (Hochst.) Baker and Delonix regia (Bojer ex Hook.). This study was initiated to assess variations in germination characteristics of seeds sown at different orientations with respect to the micropyle position and to identify the sowing position that gives the best seed germination outcomes for those tree species when measured by selected parameters.

Results: Sowing position where the micropyle of the seed was directed downward has shown the best result with regard to speed of germination, mean germination time, mean daily germination, peak value, germination value, and germination percents for both tree species and was significant for D. regia.

Conclusions: It is essential to consider the effects of different sowing positions in achieving production targets with good quality seedlings. The seeds of $D$. regia should be sown in nurseries carefully by positioning its micropyle downward. Moreover, seeds sown with the micropyle positioned upward showed the least results in terms of germination for both tree species (significant in D. regia).
\end{abstract}

Keywords: Germination conditions; Micropyle orientation; Positive geotropism; Seed

\section{Introduction}

For years, several countries have experienced severe loss of forest cover and consecutive land degradation. As part of the global forest clearance, Ethiopia has lost approximately $40 \%$ of its natural forest cover in nearly the last 10 decades (Evans 1992; Legesse 1995). Large-scale clearance and conversion of forest lands to agricultural and other land use types, the increased human consumption of various forest products, settlement expansion, and intense grazing, which are mostly linked to the exponentially growing population, are major drivers of this fact. As a result, most of the benefits that everyone gets from these resources become limited or totally unavailable. Often, such conversions of natural forests into major land use types accompanied by changes in climatic condition of most regions have negative impact on environmental as well as biological components (Grainger

* Correspondence: kebedewolka@gmail.com

Wondo Genet College of Forestry and Natural Resources, P.O. Box 128, Shashemene, Ethiopia
1993). Such environmental changes are further aggravated by the rapidly increasing population number throughout the world placing high pressure on the remaining natural resources (mainly forests), which calls for urgent action.

In order to solve the problems related to deforestation and meet the ever increasing demands of the growing population, which will require sustainable use of forest products on sustainable manner, conserving and wise utilization of the remaining forests and supporting it with additional tree planting are crucial. However, several factors are known to have effects on the production of quality seedlings with required numbers. These factors include the availability of essential nutrients, proper soil mixture, sowing depth, viability of seeds, sowing date, and timing and frequency of watering. These determine the germination power of the seeds, the number of seedlings to be emerged, and their quality. Several studies have been carried out on the impacts of these factors and how they are affecting the raising of a required number of seedlings of required quality. For example, 
sowing depth can influence germination rate and amount and, thus, final number of seedlings in the seed beds (Duryea and Landis 1984). The nature of the seed itself is a key element in plant production and can influence the success and failures of both natural and artificial regeneration (Bichi 2012).

While some factors could better be controlled, there still exists variation on the uniformity of germination and number of seedlings emerged above the ground. Some seeds germinate rapidly, others slowly, and some fail to appear above the ground resulting in germination irregularities by extending the time needed for the normal germination. This has occurred even when seeds received similar treatment before and after seed sowing, which might be linked to the different sowing positions, especially in case of lager seeds. Besides, it may also have an effect on the number of seedlings to be emerged after sowing. Such irregular germination extending over a long time is bound to create several practical problems including occupation of nursery beds by the seedlings for long periods of time thereby increasing production costs due to the need for extended tending operations such as watering, weeding, root pruning, and guarding (Legesse 1995).

The endemic multiple use tree species Millettia ferruginea (Hochst.) Baker, is widely grown in southeastern, northern, central, southwestern, and the northwestern highlands of Ethiopia at altitudes ranging from 1000 to $2800 \mathrm{~m}$. This tree species is commonly retained on farmlands and homesteads in association with annual and perennial crops as well as on homesteads and as shade tree of coffee (Tadesse 1998; Hailu et al. 2000). Delonix regia (Bojer ex Hook.) is also widely grown in Ethiopia, commonly at roadsides and for ornamental purposes. Because of increasing interest and effort to grow these tree species, understanding the effective techniques of positioning seeds; micropyles at the initial stage of seed sowing is crucial. Research reports and other information on proper positioning of these species micropyles in field conditions are lacking.

Therefore, this study was initiated to assess variations in germination characteristics of $M$. ferruginea and $D$. regia seeds sown at different orientations with respect to the micropyle position and to identify the sowing position that gives the best seed germination outcomes for those tree species when measured by selected parameters.

\section{Research methods and materials used Description of the study area}

The study was carried out at the Wondo Genet College of Forestry and Natural Resources' nursery with an area of 1.2 ha and slope varying between 2 and $4 \%$. It is situated $260 \mathrm{~km}$ south of Addis Ababa and $13 \mathrm{~km}$ from Shashemene in Southern Nations Nationalities Peoples
Regional State at $7^{\circ} 6^{\prime} \mathrm{N}, 38^{\circ} 37^{\prime} \mathrm{E}$. The altitude varies between 1800 and $2100 \mathrm{~m}$ above sea level.

It occupies both natural and man-made forests. The natural forest is classified as undisturbed, slightly disturbed, disturbed, and very disturbed forest. The natural forest can be described as a "montane forest" containing major species like Celtis africana, Cordia africana, Croton macrostachyus, Albizia gummifera, Podocarpus falcatus, and Millettia species. The main exotic species planted include Cupressus lusitanica, Grevillea robusta, Pinus patula, and different Eucalyptus species.

The climatic condition of the site is characterized by alternating wet and dry seasons and is bimodal, largely reflecting the annual movements across the country of an equatorial low pressure zone, caused by the convergence of dry northeasterly winds with moist winds of southwesterly origin (Erikson and Stern 1987, Zebene 1990). A period of dry weather is experienced, with little or no cloud cover from December to February. The main rain season occurs from May to September. The annual average rainfall is $1200 \mathrm{~mm}$ but varies between 700 and $1400 \mathrm{~mm}$. The mean temperature throughout the year is about $19^{\circ} \mathrm{C}$.

\section{Methods}

The study was carried out in the field at the nursery of Wondo Genet College Forestry and Natural Resources using seeds of $M$. ferruginea which were obtained from Awassa seed center, and D. regia, which was collected around the Langano area.

Owing to the uniformity of environmental factors of the study site, a completely randomized design (CRD) was selected and applied. The field layout was made to have four treatments that were four different sowing positions with respect to micropyle positions as described below in Table 1 and illustrated in Fig. 1.

A nursery soil mixture of 5:3:2 ratios of forest soil, compost, and sand, respectively, was used, and polyethylene tube with a diameter of $8.5 \mathrm{~cm}$ was used for all treatments. Before sowing, seeds of $D$. regia were treated with hot water for half a day (Azene 1993; Bichi 2012) to break the dormancy and enhance seed germination. The pre-sowing treatment was not applied to the M. ferruginea seeds, as its seeds are not dormant. In each treatment, having three replications, 35 randomly picked apparently healthy seeds were sown in polyethylene tube filled with the soil mixture indicated above. Accordingly, 420 pure seeds were used and sown for each tree species. The soil mixture, weeding, size of polyethylene tube, sowing depth and date, amount and timing of watering, and other nursery management activities were kept constant for all treatments and replications. Watering is done twice a day early in the morning at 7:00 a.m. and in the afternoon at 5 p.m. Germination, for this 
Table 1 Treatment and their description

\begin{tabular}{ll}
\hline Treatment & Description \\
\hline Mfu & $\begin{array}{l}\text { Millettia ferruginea seed sown by positioning micropyle } \\
\text { upright (vertical) }\end{array}$ \\
Mfd & $\begin{array}{l}\text { Millettia ferruginea seed sown by positioning micropyle } \\
\text { downward } \\
\text { Mfh }\end{array}$ \\
Millettia ferruginea seed sown by positioning micropyle \\
horizontal \\
Dru & $\begin{array}{l}\text { Millettia ferruginea seed sown randomly, specific } \\
\text { positioning of micropyle is not considered (control) }\end{array}$ \\
Drd & $\begin{array}{l}\text { Delonix regia seed sown by positioning micropyle } \\
\text { upright (vertical) }\end{array}$ \\
Drh & $\begin{array}{l}\text { Delonix regia seed sown by positioning micropyle } \\
\text { downward }\end{array}$ \\
Drc & $\begin{array}{l}\text { Delonix regia seed sown by positioning micropyle } \\
\text { horizontal }\end{array}$ \\
& $\begin{array}{l}\text { Delonix regia seed sown randomly, specific positioning } \\
\text { of micropyle is not considered (control) }\end{array}$ \\
\hline
\end{tabular}

study, is described as a process by which the dormant embryo grows out of the seed coat and establishes itself as a seedling (Bichi 2012). It was monitored for 40 days. At the 40th day, seeds that did not germinate were checked whether dead, alive, or missing for unknown reasons.

The following seed germination-associated parameters were calculated (Gairola et al. 2011), and the variations in those parameters were analyzed statistically using one-way ANOVA and Student-Newman-Keuls (SNK):

\section{i. Speed of germination}

Speed of germination was calculated by the following formula given by Gairola et al. (2011) and Kebede and Yidinekachew (2014).

Speed of germination $=n_{1} / d_{1}+n_{2} / d_{2}+n_{3} / d_{3}+---+$ $n_{m} / d_{m}$

where, $n=$ number of germinated seeds; $d=$ number of days; $m=m$ th round count $/$ days

ii. Mean germination time (MGT)
Mean germination time was calculated by the formula given by Ellis and Roberts (1981)

MGT $=n_{1} * d_{1}+n_{2} * d_{2}+---n_{m} \times d_{3} /$ Total number of days

Where, $n=$ number of germinated seed; $d=$ number of days; $m=m$ th round count $/$ days

iii. Mean daily germination (MDG)

Mean daily germination can be calculated by the following formula given by Czabator (1962) and Kebede and Yidinekachew (2014)

MDG = Total number of germinated seeds/Total number of days

iv. Peak value (PV)

Peak value was calculated by the following formula given by Gairola et al. (2011).

$\mathrm{PV}=$ Highest seed germinated/Number of days

\section{v. Germination value (GV)}

Germination value was calculated by the following formula given by Czabator (1962).

$\mathrm{GV}=\mathrm{PV} * \mathrm{MDG}$

For all treatments, seed germination percent in every fourth day was computed starting from the fourth day after the first seed germinated, and a one-way ANOVA was applied to compare the significance of variation between treatments. To identify the significantly varying mean of one treatment to another, SNK was used.

\section{Results}

In this study, the objective of assessing the speed of germination, mean germination time, mean daily germination, peak value, germination value, and germination percent of the two tree species was addressed by sowing positions that gave better results of germination. This indicated that under the given conditions, it is possible to rapidly produce vigorous seedlings, while weak or



Fig. 1 Illustrations for the sowing orientation with respect to micropyle (from left to right: vertical (upright), downward, and horizontal positioning of micropyle) 
delayed germination is often fatal. The higher the values in those germination characteristics, the better the germination rate of the seeds. Accordingly, the results obtained for each sowing position in each tree species are presented as follows.

\section{Germination of $M$. ferruginea seeds sown at different micropyle positions}

The speed of germination for seeds which micropyle was positioned downward (Mfd) was figuratively the highest (Table 2) and followed by Mfh. Even though the result is not significant, the lowest speed of germination was observed in Mfu, which indicates that sowing by positioning micropyles upward delays the germination speed. The lowest speed of germination was recorded for treatment Mfu. Similarly, the mean germination time for Mfu was lowest whereas the highest was observed for Mfd followed by Mfh. The mean daily germination, peak value, and germination values are similar with the parameters described above. Peak value for Mfd was significantly higher than the Mfu. Even though there was no significant variation, the Mfd had the highest germination percent at all four calculated date intervals (12th, 16 th, 20th, and 24th date).

The same letter across the row shows significantly different treatment.

\section{Germination of $D$. regia seeds sown at different micropyle positions}

The D. regia seed sown as Drd showed significantly greater speed of germination compared to all other treatments (Table 3). There was no significant difference between other treatments (Dru, Drh, and Drc). The mean germination time for the treatment Drd was also significantly greater than other treatments. Other treatments (Dru, Drh, Drc) were not significantly different to each other. The Dru showed the lowest value indicating that positioning the micropyle upwards while sowing delays germination in a seed with such morphology. The significantly lowest $(P<0.05)$ mean daily germination and peak values were observed in Dru, and the Drd showed greater results when compared to other treatments. The germination value of Dru was significantly lower than Drd.

Among treatments, the germination percent showed no significant variation on 11th and 15th days from the date of sowing. On day 19, treatment Drd showed significantly higher germination compared to the other three treatments. There was no significant difference between other three treatments (Dru, Drh, and Drc). On day 23 from the date of sowing, the germination percent for Drd was significantly higher than Dru and Drc. On this date, the Dru showed a significantly lower germination percent than Drh. The germination percent for Dru on 27th day from the date of sowing was significantly lower than other treatments, but other treatments (Drd, Drh, and Drc) showed no significant difference.

The same letter across the row shows significantly different treatments.

\section{Discussion}

Creating a forest cover can be accomplished in several ways; for example, initiating natural regeneration (if any natural vegetation exists on the site) and direct sowing on the site, which can be applied in humid and subhumid areas for species with very rapid initial growth and when seeds are plentiful, affordable, and have reliable germination (ILO \UNDP $\backslash$ 1993). However, these methods do have their own difficulties in that natural regeneration may not be always possible, and direct sowing has sporadic germination, damage by predators (both to seeds and to the young plants), and uncertainties over the timing of operations (Wood and Burley 1991). As a result, in creating and increasing forest cover, trees often have to be planted by raising seedlings inside nurseries. For its success, it requires raising seedlings of the right species, size, number, and quality (ILO \UNDP\1989). Often, getting such seedlings with required quality and

Table 2 Millettia ferruginea seed germination (speed of germination, mean germination time, mean daily germination, peak value, germination value, and germination percents (mean $\pm \mathrm{SE}$ ))

\begin{tabular}{|c|c|c|c|c|c|}
\hline Parameters & Mfu & Mfd & Mfh & Mfc & $p$ value \\
\hline Speed of germination & $5.12 \pm 2.09$ & $14.43 \pm 1.51$ & $10.31 \pm 1.72$ & $9.46 \pm 3.760$ & 0.14 \\
\hline Mean germination time & $72.86 \pm 25.05$ & $168.86 \pm 14.96$ & $136.64 \pm 20.56$ & $119.08 \pm 44.18$ & 0.19 \\
\hline Mean daily germination & $0.40 \pm 0.11$ & $0.76 \pm 0.06$ & $0.69 \pm 0.09$ & $0.57 \pm 0.20$ & 0.26 \\
\hline Peak value & $0.48 \pm 0.12 \mathrm{a}$ & $1.20 \pm 0.10 a$ & $0.86 \pm 0.14$ & $0.78 \pm 0.23$ & 0.07 \\
\hline Germination value & $0.22 \pm 0.11$ & $0.93 \pm 0.15$ & $0.62 \pm 0.18$ & $0.53 \pm 0.32$ & 0.19 \\
\hline Germination percent at 12 th date & $5.71 \pm 4.36$ & $34.29 \pm 7.19$ & $15.24 \pm 5.04$ & $20.00 \pm 13.50$ & 0.19 \\
\hline Germination percent at 16 th date & $18.10 \pm 9.62$ & $52.38 \pm 4.15$ & $42.86 \pm 5.95$ & $36.19 \pm 13.74$ & 0.13 \\
\hline Germination percent at 20th date & $26.67 \pm 6.67$ & $52.38 \pm 4.15$ & $46.67 \pm 6.87$ & $39.05 \pm 13.43$ & 0.24 \\
\hline Germination percent at 24 th date & $27.62 \pm 7.62$ & $52.38 \pm 4.15$ & $47.62 \pm 6.25$ & $39.05 \pm 13.43$ & 0.26 \\
\hline
\end{tabular}


Table 3 Delonix regia seed germination (speed of germination, mean germination time, mean daily germination, peak value, germination value, and germination percents (mean \pm SE))

\begin{tabular}{|c|c|c|c|c|c|}
\hline Parameters & Dru & Drd & Drh & Drc & $p$ value \\
\hline Speed of germination & $2.91 \pm 1.33 \mathrm{C}$ & $11.95 \pm 1.94 a b c$ & $6.57 \pm 0.78 a$ & $6.04 \pm 0.97 b$ & 0.01 \\
\hline Mean germination time & $49.94 \pm 16.89 c$ & $192.24 \pm 28.34 a b c$ & $119.01 \pm 13.20 \mathrm{a}$ & $108.13 \pm 16.43 b$ & 0.01 \\
\hline Mean daily germination & $0.31 \pm 0.05 a b c$ & $0.78 \pm 0.11 \mathrm{a}$ & $0.67 \pm 0.06 b$ & $0.65 \pm 010 c$ & 0.02 \\
\hline Peak value & $0.33 \pm 0.05 a b c$ & $0.83 \pm 0.10 a$ & $0.69 \pm 0.07 b$ & $0.68 \pm 0.10 c$ & 0.02 \\
\hline Germination value & $0.11 \pm 0.03 a$ & $0.67 \pm 0.17 a$ & $0.47 \pm 0.09$ & $0.47 \pm 0.15$ & 0.06 \\
\hline Germination percent at 11 th date & $1.90 \pm 1.90$ & $1.90 \pm 1.90$ & $0.00 \pm 00$ & $0.00 \pm 00$ & 0.60 \\
\hline Germination percent at 15 th date & $5.71 \pm 5.71$ & $29.52 \pm 8.30$ & $6.67 \pm 0.95$ & $11.43 \pm 2.86$ & 0.04 \\
\hline Germination percent at 19th date & $7.62 \pm 5.04 c$ & $50.48 \pm 5.79 a b c$ & $23.81 \pm 1.90 \mathrm{a}$ & $20.00 \pm 4.95 b$ & 0.00 \\
\hline Germination percent at 23rd date & $11.43 \pm 3.30 \mathrm{ac}$ & $53.33 \pm 6.87 b c$ & $35.24 \pm 7.80 \mathrm{a}$ & $28.57 \pm 4.36 b$ & 0.01 \\
\hline Germination percent at 27th date & $23.81 \pm 4.15 \mathrm{abc}$ & $60.00 \pm 8.25 a$ & $51.43 \pm 4.95 b$ & $50.48 \pm 7.80 c$ & 0.02 \\
\hline
\end{tabular}

number is determined while they are in the nurseries. Hence, various factors that may impact quality seedling production need to be considered and properly controlled. In this study, the seed sowing position with respect to micropyle orientation has been tested for its impact on the germination and quality of seedlings. According to the results obtained, sowing seeds of $M$. ferruginea and D. regia with the micropyle of the seed positioned downward is most advantageous.

Obviously, with seed germination, growth of a plant begins. The first root, called the radicle, will grow out of the seed through the micropyle, and the micropyle is part of the seed where water imbibes into the seed and enhances germination. Naturally, the shoot of the germinating seed has a negative geotropism, and the radicle has a positive geotropism. In managing seed sowing processes, the orientation of micropyle is related with supporting the upcoming response of the seedling to the stimulus (gravity). The downward curvature of the root tipped toward the center of gravity is influenced by biochemical and environmental factors and is considered as an essential characteristic for plant survival (He and South 2006). According to Coutts (1989), if the root is displaced from its vertical position or the seeds oriented vertically upward with respect to micropyle, the tip of the root bends downward. Similarly, the roots of the seed sown by positioning the micropyle vertically upright have to curve over the seed itself in order to grow in their normal (downward) direction (Fig. 1).

The germination condition influenced by orientation of seed is also related to the effect it creates on physiological processes during germination. In seeds of some plant species with higher weight in which extra energy is required to elongate hypocotyls, positioning the micropyle upright reduces germination as explained earlier. In addition to the abovementioned reasons, physiological processes controlled by plant growth hormone have a role. In such situation, the flow of auxin produced in the root tip has limited flow to reach to part of the root with required extent to influence the growth positively (Bhat 2011). This abnormal chemical process results to poor morphological development and influence germination condition, among others. Therefore, poor metabolic integrity, additional energy demand, and hormone distribution lower the germination results in D. regia seed (Mahgoub 1995; Masilamani et al. 1999).

The roots of the seeds sown by positioning the micropyle horizontally still have to bend downward in order to grow correctly, even though the bending appears not difficult to the extent of vertically upright positioned orientation. Therefore, for this treatment, better germination results were observed compared to positioning the micropyle vertically upright.

For seeds with medium and large morphology, it was easier for roots to emerge and grow if the micropyle is directed downward, following positive geotropism. When the micropyle is oriented downward, the roots of the seed grew easily and directly downward, with no need for bending. Therefore, the observed higher speed of germination, mean germination time, mean daily germination, peak value, germination value, and germination percent for seeds sown by positioning the micropyle downward is related to the ease for the radicle to emerge and grow downward in the normal direction. In general, plant roots grow downward for as they are positively geotropic and hydrotropic. Exploration of nutrients from soil and increasing the framework for anchorage are also advantage of the correctly growing roots.

The speed, uniformity, and rate of germination that varied because of the micropyle sowing position have implications on seedling quality. The seedlings whose roots grow properly (without curving) will establish well for its function, which can improve the performance of seedlings. The curving roots at early stages and non-uniform germination negatively influence seedling performance. 


\section{Conclusions}

To meet the ever increasing natural resource demands of the growing population and to solve problems related to deforestation, one has to conserve and wisely utilize the remaining forests. These remaining forests, by any means, cannot satisfy the needs of human beings nor are sufficient to attain an ecological balance. Hence, much effort has to be put in place to raise a sufficient number of quality seedlings in nursery settings. These efforts can increase the tree covers of a country so that some, but not all, problems related to deforestation can be alleviated.

A successful plantation establishment requires raising a seedling of the right species, size, number, and quality. Such requirements of seedlings for successful plantations are determined while they are raised in nurseries. The numbers of seedlings to be raised in the nursery also determines the number of laborers in the nursery, the size of the nursery, the area to be planted, and thus labor costs for establishing a nursery and preparing plantation sites. Therefore, once we invest such costs, a special care should be given to produce the required number and quality of seedlings. However, obtaining the required number and quality of seedlings is influenced by many factors; among these factors, the sowing position is indispensible.

The treatment Mfd and Drd, where the micropyle of the seeds was directed in the downward position, has shown to be the best germination condition with respect to the considered parameters in both tree species. The highest germination results for these treatments will help to produce more vigorous seedlings that fit to the field conditions and avoid unnecessary nursery delays and non-uniformity in germination and hence save cost, energy, and time. The treatment where the micropyle of the seeds was sown in the upright position has shown the least desired results; other treatments possessed intermediate results in both tree species. The results are statistically significant for $D$. regia with regard to most considered germination parameters. Thus, the micropyle sowing position needs to be critically managed for this species where the micropyle is placed in the downward position for better germination and seedling growth.

\footnotetext{
Abbreviations

Drc: Delonix regia seed sown randomly; Drd: Delonix regia seed sown by positioning micropyle downward; Drh: Delonix regia seed sown by positioning micropyle horizontal; Dru: Delonix regia seed sown by positioning micropyle upright (vertical); GV: germination value; ILO: International Labour Organization; MDG: mean daily germination; Mfc: Millettia ferruginea seed sown randomly; Mfd: Millettia ferruginea seed sown by positioning micropyle downward; Mfh: Millettia ferruginea seed sown by positioning micropyle horizontal; Mfu: Millettia ferruginea seed sown by positioning micropyle upright (vertical); MGT: mean germination time; PV: peak value; SNK: Student-Newman-Keuls; UNDP: United Nations Development Program.
}

\section{Competing interests}

The authors declare that they have no competing interests.

\section{Authors' contributions}

Both researchers participated in designing the research idea, field data collection, data analysis, interpretation, and report writing. Both authors read and approved the final manuscript.

\section{Authors' information}

TZ is a lecturer in forestry sciences at Hawassa University, Wondo Genet College of Forestry and Natural Resources. He is a PhD fellow in Ghent University, Belgium. KW is an Assistant professor at Hawassa University, Wondo Genet College of Forestry and Natural Resources. He mainly teaches and undertakes research on soil science, soil erosion, soil and water conservation, and watershed management. He published 11 articles mainly in international journals.

\section{Acknowledgements}

The authors thank Tatum Branaman for language editing and anonymous reviewers.

Received: 28 February 2015 Accepted: 19 June 2015

Published online: 01 July 2015

\section{References}

Azene B (1993) Useful trees and shrubs for Ethiopia. Regional Soil Conservation Unit ISIDA. Technical Hand book - No. 5. Swedish International Development Agency, Nairobi, Kenya.

Bichi AM (2012) Different pre-germination treatments and Delonix regia seeds. Jorind 10(2):24-29

Bhat RP (2011) Effect of orientation of seed placement on seedling emergence in some species of calamus. Advances in Bioresearch 2(2):86-89

Coutts MP (1989) Factors affecting the direction of growth of tree roots. Forest tree physiology. Ann Forest Sci 46:277-287

Czabator FJ (1962) Germination value: an index combining speed and completeness of pine seed germination. Forest Sci 8:386-395

Duryea M L and Landis T D (1984) Forest Nursery Manual. Hague, Martinus Nijhoff \Dr.W.Junk Publishers, the Netherlands.

Ellis RH, Roberts EH (1981) The quantification of ageing and survival in orthodox seeds. Seed Sci Tech 9:373-409

Erikson H, Stern M (1987) A soil study at Wondo Genet Forestry Resources Institute. Ethiopia, SUAS, International Rural Development Center, Uppsala

Evans J (1992) Plantation forestry in tropics. 2nd ed. Oxford University New York: Oxford University Press, Walton Street, Oxford Ox2 6DP.

Gairola KC, Nautiyal AR, Dwivedi AK (2011) Effect of temperatures and germination media on seed. Germination of Jatropha Curcas Linn. Advances in Bioresearch 2(2):66-71

Grainger A (1993) Controlling tropical deforestation. Earthes can Publication, London

Hailu T, Negash L, Olsson M (2000) Millettia ferruginea from Ethiopia: impacts on soil fertility and growth of maize. Agroforestry System 48:9-24

He D, South DB (2006) A review on mechanism of plant geotropism: developing trend in research on pine root geotropism. Afr J Agr Res $1(4): 78-84$

ILO\UNDP\ (1989) An illustrated technical guide and training manual No-7. International Labour Organisation, Switzerland.

ILO\UNDP\ (1993) An illustrated technical guide and training manual No-7. International Labour Organisation, Switzerland.

Kebede W, Yidinekachew H (2014) Effect of seed storage period and condition on viability of Jatropha curcas L. seed. Res J Forest 8(2):56-62

Legesse N (1995) Indigenous Trees of Ethiopia. Department of Biology-Adiss Ababa University, Addis Ababa, Ethiopia

Loha A, Tigabu M, Teketay D (2008) Variability in seed- and seedling-related traits of Millettia ferruginea, a potential agroforestry species. New Forests 36:67-78

Masilamani P, Gurudev BS, Chinnusamy C, Annadurai (1999) Influence of seed orientation and depth of sowing on germination and vigour of Anjan (Hardwickia binata Roxb). Short communication. Tropical Agricultural Research and Extension 2(1):76-78

Mahgoub S (1995) The influence of positioning of seed during sowing on seed germination of some tree species in relation to germination type and seed shape. In: Proc. IUFRO Symposium on innovations in Tropical Tree Seed Technology. Arusha, Tanzania, pp 149-159 
Tadesse H (1998) Effects of Millettia ferruginea on soil fertility and growth performance of maiz. MSc in Forestry Programme Thesis Work Skinns Katterbers Wood PJ, Burley J (1991) A Tree for all Reason - The Introduction and Evaluation of Multipurpose Trees for Agroforestry. ICRAF, Nairobi, Kenya

Zebene A (1990) Silvicultural Management of Cupressus Iusitanica and Grevillea robusta in Southern Ethiopia. University of Wales (U.C.N.W., Bangor: Agricultural and Forest Sciences)

Submit your manuscript to a SpringerOpen ${ }^{\odot}$ journal and benefit from:

- Convenient online submission

- Rigorous peer review

- Immediate publication on acceptance

- Open access: articles freely available online

- High visibility within the field

- Retaining the copyright to your article

Submit your next manuscript at $\gg$ springeropen.com 